\title{
Cyclic changes in oxygenation based on foraminiferal microhabitats: Early-Middle Pleistocene, Lucania Basin (southern Italy)
}

\author{
SIMONA STEFANELLI \\ Geology and Geophysics Department, University of Bari, Via Orabona 4, 70125 Bari, Italy (e-mail: stefanelli@geo.uniba.it).
}

\begin{abstract}
In the Pleistocene Montalbano Jonico composite section (southern Italy) the microhabitat preferences of the benthic foraminifera have been determined by comparison with data on living forms. The stratigraphic distribution of the different living positions seems to be related to the cyclic oxygen fluctuations recorded in the succession. In the high-oxygenated phases, when the oxygenated zone within the sediment column is wide, the assemblages show a distinct vertical microhabitat distribution. In the low-oxygenated phases, when the minor oxygen availability at the bottom-water interface reduces the oxygen penetration within the sediment, infaunal microhabitat is the preferred living depth.

In order to quantify the oxygen fluctuations recorded in the succession, a palaeo-oxygen curve is reconstructed testing Kaiho's benthic foraminiferal oxygen index (BFOI) in the equation: $y=1.686+$ $0.033337 x$. In general, good correlations are observed between the dissolved oxygen regimes and the benthic assemblage composition. The low-oxygenated phases are identified with the low-medium oxic regime and the high-oxygenated phases with the high oxic regime.

In the deeper part of the composite section, oxygen has played an important role on the foraminiferal assemblage composition. In contrast, in the shallower part, a combination of oxygen and sea-level changes regulates the distribution and composition of the assemblages. J. Micropalaeontol. 23(1): 81-95, May 2004.
\end{abstract}

\section{INTRODUCTION}

The microhabitat category of benthic foraminifera depends on their living depth in the sediment. If the fauna lives on the top of the sediment, the microhabitat is defined as epifaunal; if the fauna lives in the sediment, the microhabitat is defined as shallow infaunal (depths of $0.5-2 \mathrm{~cm}$ ) or deep infaunal (at depths greater than $2 \mathrm{~cm}$ ) (Murray, 1991; Barmawidjaja et al., 1992; Linke \& Lutze, 1993; Buzas et al., 1993; Jorissen et al., 1995). Most benthic foraminifera seem to prefer the sedimentwater interface where the most abundant resources are available (van der Zwaan et al., 1999). Many factors have been proposed to explain benthic foraminiferal microhabitat distribution. Two of them, oxygen concentration and organic matter flux (food availability), seem to play an important role (van der Zwaan et al., 1999). In most cases, these factors cannot be separated and the combination of their effects is considered to be the real regulator of benthic foraminifera microhabitat position (Jorissen et al., 1992; Linke \& Lutze, 1993; Jorissen et al., 1995; Jorissen, 1999).

Jorissen et al. (1995) and Loubere (1997) demonstrated that the redox zone depth, which depends on organic flux and oxygen, regulates the microhabitat position. When the redox zone is deep, the oxygen content is high and organic flux is low or moderate. The first centimetres of sediments are rich in epifaunal and shallow infaunal taxa, whereas deeper layers contain intermediate and deep infaunal species. As the oxygen demand increases, the redox zone rises, reducing the oxygenated levels and, thus, determining an important change in benthic faunal compositions. In this ecological regime, taxa having infaunal microhabitats dominate the assemblages. With further loss of oxygenation the infaunal taxa that are less tolerant to low oxygen conditions will be gradually replaced by infaunal taxa with greater resistance to lower oxygen conditions (van der Zwaan \& Jorissen, 1991; Barmawidjaja et al., 1992).
Some investigations have demonstrated, however, that foraminiferal microhabitats should not be classified according to a static concept but according to a dynamic process, since some species are able to change their life position (Jorissen, 1988; Buzas et al., 1993; Linke \& Lutze, 1993). The ability to change microhabitats is limited to some taxa, termed 'potentially infaunal taxa'. These are able to track seasonal fluctuations of critical oxygen levels within the sediment (Barmawidjaja et al., 1992).

Recently, Murray (2001) argued that oxygen levels and food supply largely control the benthic foraminiferal distribution only in the deep marine environments. On the contrary, in shallow marine environment, he considers that it would be too simplistic to attempt to define their distribution only in terms of oxygen and food supply, because other factors have been shown to play a major role.

In southern Italy, attention has been focused on the Montalbano Jonico composite section, which is more than $400 \mathrm{~m}$ thick. Two principal marine domains, deep and shallow, were recognized on the basis of benthic fossil assemblages (Ciaranfi et al., 1997, 2001). Since cyclic oxygen fluctuations were evident, the microhabitat preference distribution of the benthic foraminifera in the composite section was presented. The aim of this paper is to interpret the microhabitats of the Pleistocene foraminifera with reference to modern data and to use that information to infer past oxygen conditions.

\section{AREA OF STUDY}

The Montalbano Jonico composite section crops out in the Lucania basin, one of the minor basins of the Bradano Trough (Casnedi, 1988). This basin is limited westward by the external Apennines thrust belt and eastwards by the foreland carbonate units (Fig. 1a). Along the internal border, the Pliocene and Early 


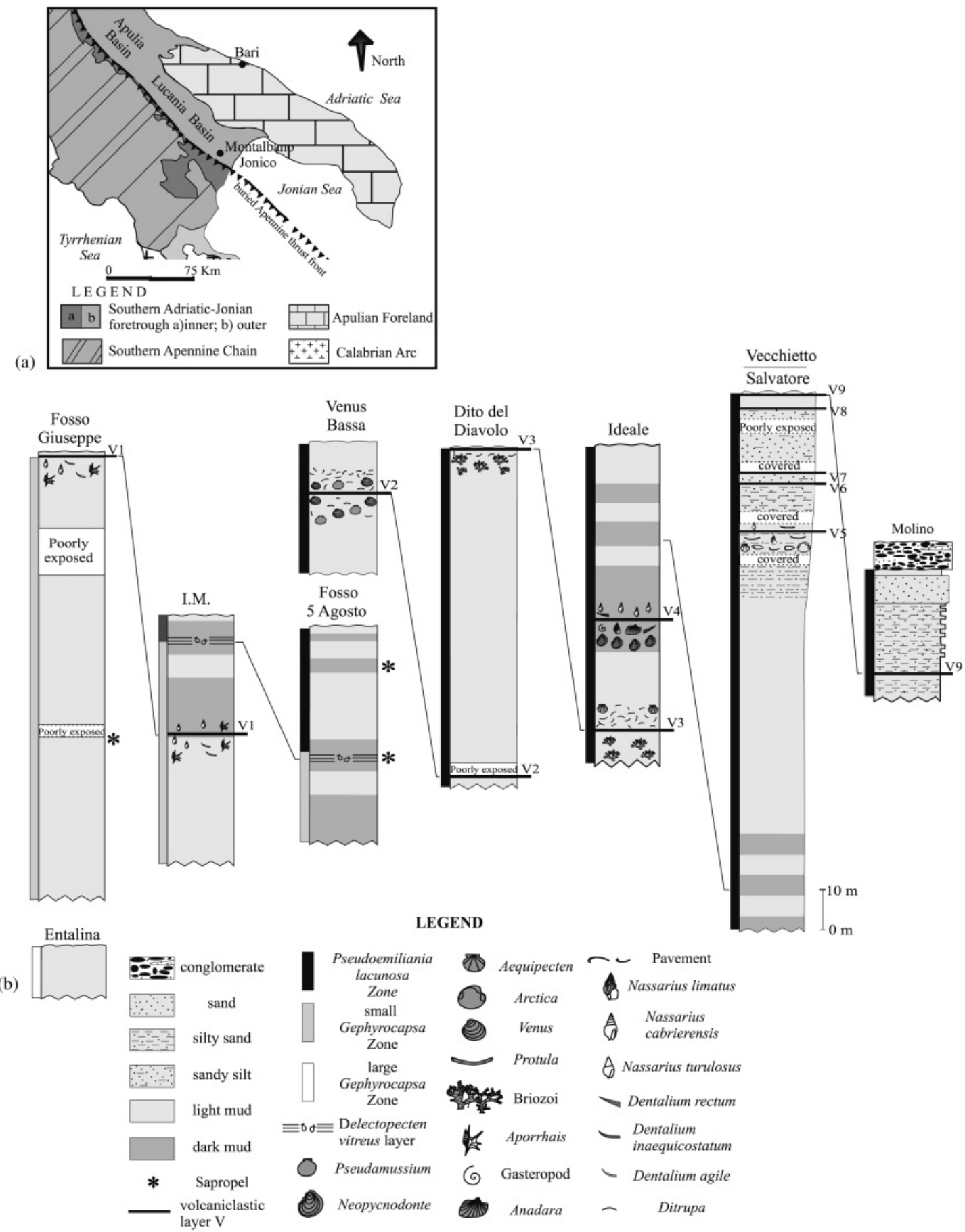

Fig. 1. (a) Location of the Lucania basin, southern Italy; (b) the selected stratigraphic sections that crop out in the area of Montalbano Jonico town. (Modified from Ciaranfi et al., 2001).

Pleistocene siliciclastic sediments were affected by strong uplift, while moderate subsidence characterized the external border (Ciaranfi et al., 1997, 2001). During the late Early Pleistocene, the more internal portion of the Lucania basin evolved due to a relative sea-level fall caused by the uplifting of the Apennine chain. Consequently, erosional truncation of land areas occurred, up to almost complete removal of Pleistocene sediments. By contrast, the depocentral areas of the Lucania basin were affected by strong subsidence that caused a relative sea-level rise. Consequently, a narrow and deep trough was formed, in which the deposition of hemipelagic sediments took place. During the Early Pleistocene, the depocentral areas and the foreland border of the Lucania basin were involved progressively in the Bradano Trough evolution caused by the moving eastward of the uplifting Apennines border. During the Middle Pleistocene, a generalized shallowing phase took place, 
causing the subaerial exposure of silty-clayey and silty-sand successions.

\section{Montalbano Jonico composite section}

In the area of Montalbano Jonico town, correlation of several exposed successions allows the reconstruction of a continuous marine succession, about $450 \mathrm{~m}$ thick, belonging to the 'Argille subapennine' Formation (Fig. 1b). The section consists of coarsening-upward deposits, from muddy clays to muddy sands, and represents one of the more recent onland marine Pleistocene successions (Ciaranfi et al., 1997, 2001). The vertical distribution of macro and micro invertebrate fossil assemblages (Ciaranfi et al., 1997; D'Alessandro et al., 2003; Stefanelli, 2003) indicates changes of the primary environmental parameters, particularly, bathymetry, sedimentation rate and oxygen content at the bottom-water interface and in sediment pore water.

The Montalbano Jonico composite section is interrupted by a gap. A lower part termed 'Interval A' and an upper part termed 'Interval B' can be identified (Fig. 2).

Interval $\mathrm{A}$ is about $168 \mathrm{~m}$ thick and is characterized by hemipelagic muds. The foraminiferal assemblages are composed of Globocassidulina subglobosa, Globobulimina affinis, Bulimina marginata, Cibicidoides sp., Hyalinea balthica, Uvigerina group 'costate forms' and Sphaeroidina bulloides (Stefanelli, 2003) and indicate the deposition of this interval in a deep sedimentary basin, consistent with the upper bathyal-lower circalittoral zone (from $500 \mathrm{~m}$ to $110 \mathrm{~m}$, fide Sgarrella \& Moncharmont Zei, 1993). A regressive trend seems to begin around the volcaniclastic layer V1 at about $115 \mathrm{~m}$ above the base. The very low diversity benthic species detected in intervals at different heights, precisely, at $40 \mathrm{~m}, 68.5 \mathrm{~m}, 70 \mathrm{~m}$, from $135 \mathrm{~m}$ to $141 \mathrm{~m}$, and $160 \mathrm{~m}$, allows the recognition of five episodes of strong oxygen deficiency. The high dominance of Globobulimina affinis, Bolivina alata, Bolivina dilatata and Brizalina spathulata in the assemblages associated with three of these episodes suggests they are sapropels, in agreement with the criteria of Cita \& Podenzani (1980), Nolet \& Corliss (1990), Sen Gupta \& Machain-Castillo (1993) and Jorissen (1999). In addition, in these intervals, Delectopecten vitreus discontinuous pavements are recognized, which are considered to be marker beds of hypoxic episodes (D'Alessandro et al., 2003).

Within the uppermost two sapropels, oxygen isotope stages 25 and 23 (Ciaranfi et al., 2001), the first occurrence of Gephyrocapsa sp. 3 and the last common occurrence of Reticulofenestra asanoi were found (Maiorano et al., 2004). Based on these data, the two sapropels correspond well to the sapropels associated with insolation-cycles 90 and 86 . The other interval is simply marked as $\mathrm{S}$ because of the absence, at the moment, of specific chrono-biostratigraphic references. Oxygen declines observed in the other intervals, i.e. SI and SII, may also be linked to rapid burial events (D’Alessandro, pers. comm).

Interval B is about $280 \mathrm{~m}$ thick and consists of muds, and silty muds and silty sands in its topmost part. The occurrence in the shallow foraminiferal assemblage, which includes individuals belonging, above all, to Elphidiidae, Miliolidae and Discorbidae (Stefanelli, 2003), indicates the deposition of this interval in a shallow sedimentary basin, consistent with the upper circalittoral-lower infralittoral zone (from about $110 \mathrm{~m}$ to 40-30 m, fide Sgarrella \& Moncharmont Zei, 1993). Interval B

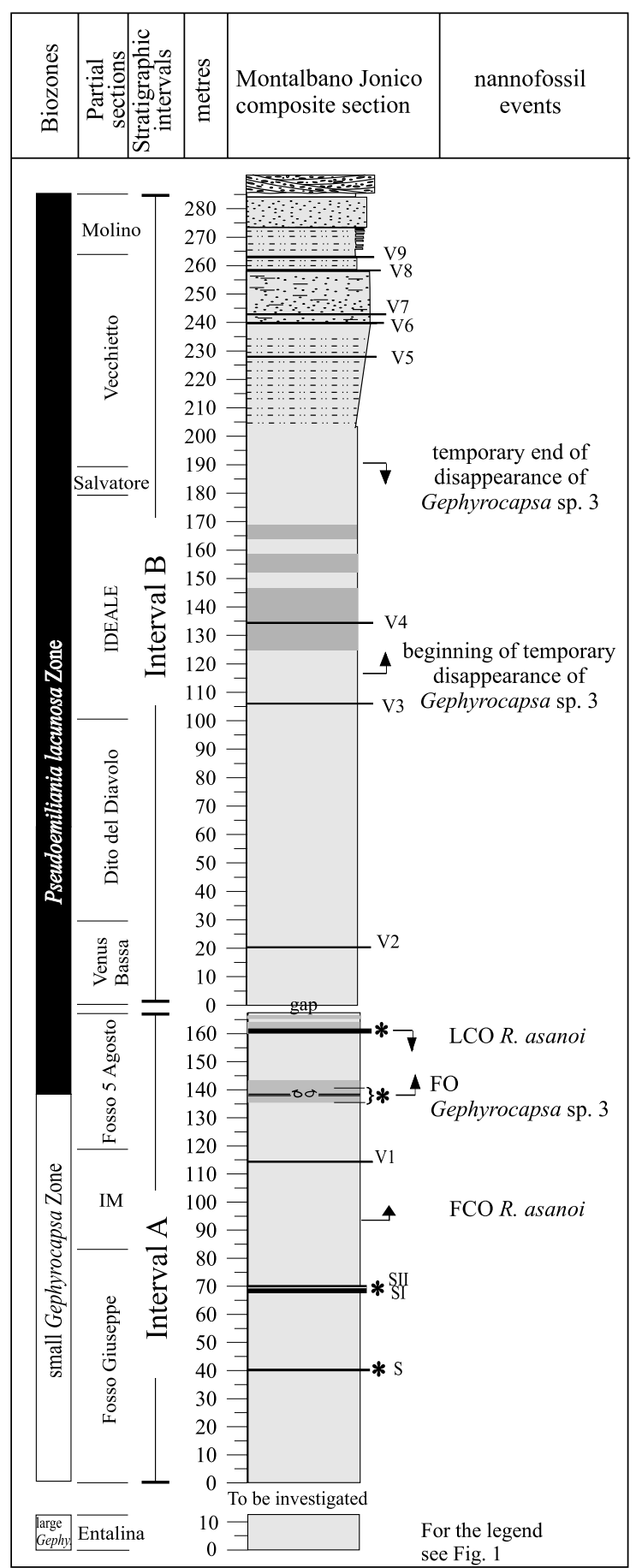

Fig. 2. The Early-Middle Pleistocene Montalbano Jonico composite section, over $400 \mathrm{~m}$ thick, plotted against the nannofossil events and biozones. (Modified from Maiorano et al., in press). The section is interrupted by a gap. A lower part (Interval A) and an upper part (Interval B) can be identified. The presence of macrofossil remains close to the volcaniclastic layers provided the precise identification of these layers, thus, allowing their use as marker beds for the reconstruction of the succession (Ciaranfi et al., 1997, 2001).

includes eight volcaniclastic horizons (V2 to V9), respectively, at $20 \mathrm{~m}, 105 \mathrm{~m}, 134 \mathrm{~m}, 228 \mathrm{~m}, 240 \mathrm{~m}, 243 \mathrm{~m}, 257 \mathrm{~m}$ and $263 \mathrm{~m}$. The volcaniclastic layers, made of ash, sands rich in volcanic 
minerals and pumice clasts, have been referred to alkaline undersatured volcanism, probably coming from a southern Italy volcanic source (Ciaranfi et al., 1996). About $10 \mathrm{~m}$ above the layer V3 and about $50 \mathrm{~m}$ above the layer V4, the beginning of the temporary disappearance of Gephyrocapsa sp. 3 and the end of its temporary disappearance, respectively, were found (Maiorano et al., 2004).

\section{MATERIAL AND METHODS}

Approximately 470 samples were analysed for their benthic foraminiferal content. The samples were collected every $70 \mathrm{~cm}$ in Interval A, every $40 \mathrm{~cm}$ around the sapropel associated with I-cycle 90 and every $1.30 \mathrm{~m}$ in Interval $\mathrm{B}$. The fraction $>63 \mu \mathrm{m}$ was examined in order to allow direct comparison with data from the literature. About 300 individuals were counted for every fraction, re-calculated as percentage values and plotted in curves to display the vertical distribution of each taxon. Species with relative frequencies above $1 \%$ were divided into three groups, according to Murray (1991), Jorissen et al. (1992), Barmawidjaja et al. (1992), Jorissen (1999) and Jorissen \& Wittling (1999): i.e. epifaunal, shallow infaunal and deep infaunal (Appendix A). Frequencies of species were then plotted in curves for each group.

As the decline in oxygen gradient principally causes a decrease in the benthic faunal diversity, the Shannon Index $H(S)$, following the Shannon-Wiener information equation (Buzas \& Gibson, 1969), was also calculated, in order to trace the changes in the faunal diversity.

In order to extract an empirical curve of oxygen concentration from the Early-Middle Pleistocene benthic foraminiferal assemblages, the equation of Baas et al. (1998): $y=1.686+$ $0.033337 x$ is used, where $y$ is the oxygen concentration in $\mathrm{ml}^{-1}$ and $x$ is the Benthic Foraminiferal Oxygen Index (BFOI) value. The BFOI is calculated following the equations of Kaiho (1994):

$$
[O /(O+D)] \times 100
$$

where $O$ and $D$ are the numbers of specimens of oxic and dysoxic indicators, respectively;

$$
\{[S /(S+D)]-1\} \times 50 \text { when } O=0,
$$

where $S$ is the number of specimens of suboxic indicators of group B.

It must be emphasized, however, that in order to enable the application of Kaiho's model to the investigated succession, some limitations are encountered. First, the number of dysoxic indicators encountered by Kaiho is much higher than the number of dysoxic indicators found in this study (Appendix B). The discrepancy is certainly related to the different water depth of the investigated section. The Montalbano Jonico composite section was deposited in a shallower sedimentary basin when compared to the sites investigated by Kaiho. Secondly, the small specimens of oxic indicators are classified as oxic rather than suboxic indicators because, in the Montalbano Jonico composite section, these species are strictly related to well-oxygenated sediments (Stefanelli, 2003). Moreover, the species Cibicidoides ungerianus and Cibicidoides pachydermus, listed in the studied assemblages, are species not specifically identified by Kaiho.
This may denote important differences in the linkages of benthic foraminiferal communities to ambient bottom-water oxygenation.

\section{RESULTS}

\section{Benthic foraminiferal trends}

In Figure 3 the stratigraphic distributional patterns of the major epifaunal and infaunal species are displayed for Interval A. Among the epifaunal taxa, Cibicidoides spp. and Hyalinea balthica are present with significant frequencies. Yet, they are rarely present in the same intervals since they present an opposite cyclic trend. Bigenerina nodosaria and Quinqueloculina group are present at low frequency. Among the shallow infaunal taxa, the most abundant species are Bulimina marginata, Cassidulina carinata and the Uvigerina group 'costate forms'. $B$. marginata increases in frequency in the lowermost part of the stratigraphic interval and between the layers $\mathrm{S}$ and SI. Then, it shows a decreasing trend in abundance towards the top. $C$. carinata is constantly present; its maximum frequency is recorded immediately below the sapropels associated with I-cycles 90 and 86. The species decreases in abundance and disappears in the layers of oxygen deficiency. The Uvigerina group 'costate forms' shows an opposite trend to C. carinata and B. marginata, with its maximum frequency recorded around the volcaniclastic layer V1. Sphaeroidina bulloides is frequent immediately below the interval $\mathrm{S}$ and shows a general increasing trend in abundance towards the top of Interval A. The Bolivina group (including the species $B$. alata and $B$. dilatata) and Brizalina spathulata are always present with frequencies less than $20 \%$, except in the intervals marked as SI, SII and in sapropels associated with I-cycles 90 and 86. In these levels they show the maximum frequency and are dominant. Gyroidina $\mathrm{sp}$. is less frequent and shows a decreasing trend in abundance towards the top. The mostly significant deep infaunal taxon is G. affinis. It is more abundant in the stratigraphic portion below V1 and decreases in abundance towards the top. The peaks of maximum frequency are recorded in S, SI, SII and in the sapropel associated with I-cycle 90. Also frequent are G. subglobosa, Melonis sp. and Textularia sp. The former taxa decrease in abundance towards the top and show an opposite trend to Textularia sp. These taxa, however, disappear in the layers of oxygen depletion.

In Figure 4, the distribution of the microhabitat groups immediately below, across and above the sapropel layers and the intervals SI and SII is plotted together with the $H(S)$ values. In these layers, the epifaunal group disappears and the $H(S)$ values strongly decrease. The assemblages are characterized by a great number of individuals, belonging to the shallow infaunal species B. alata, B. dilatata and B. spathulata and to the deep infaunal species $G$. affinis.

Focusing on the distributional patterns within the intervals $\mathrm{S}$, SII and the sapropel unit associated with I-cycle 90, G. affinis and Bolivina group are never simultaneously present in the assemblages. G. affinis dominates the assemblage at the bottom layers and the Bolivina group the assemblage at the top. In SIII the assemblage is rich in individuals of $G$. affinis. Conversely, the Bolivina group dominates the assemblage within the sapropel unit associated with I-cycle 86. 
Pleistocene foraminiferal microhabitats
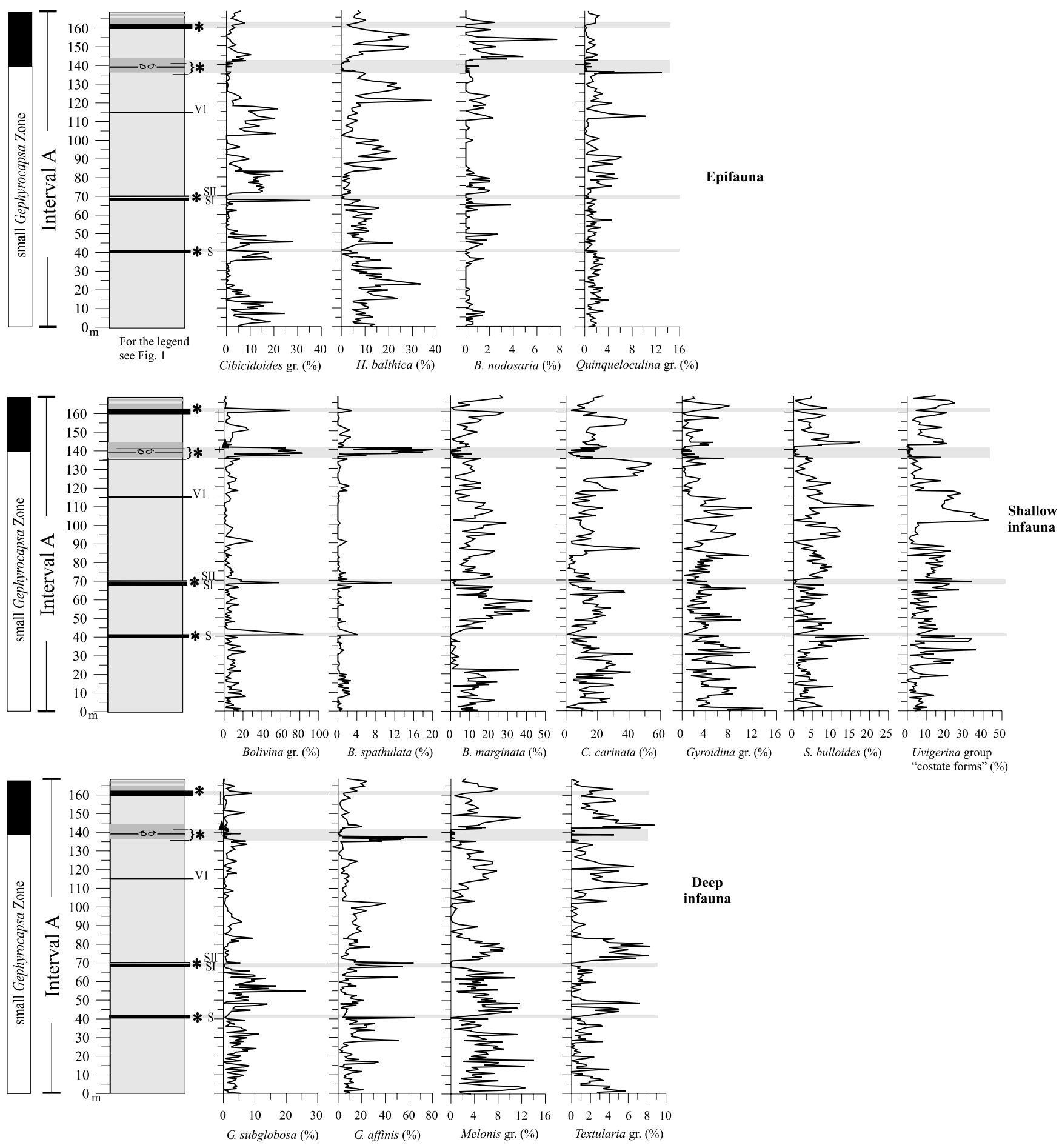

Fig. 3. Stratigraphic distribution of the most representative taxa in Interval A.

In a short interval, between SI and SII and within the sapropel associated with I-cycle 90, an increase in abundance of the shallow infaunal taxa $C$. carinata and Uvigerina 'costate forms' group that replace Bolivina and G. affinis, is observed also associated with the increase of $H(S)$ values.

In Figure 5 the distributional patterns of the most significant epifaunal and infaunal species are displayed for Interval B.
Elphidium advenum, Elphidium complanatum, Elphidium crispum and Quinqueloculina spp. are the most representative epifaunal taxa that show cyclic trends of rich and poor intervals. In the shallow infaunal group, different distributional patterns are observable. Protoelphidium granosum, Cribroelphidium decipiens and Ammonia beccarii increase in frequency in the intervals in which C. carinata, B. marginata and Valvulineria sp. are absent 
Sapropel unit associated with I-86

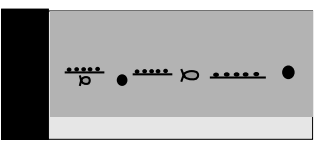

Sapropel unit associated with I-90
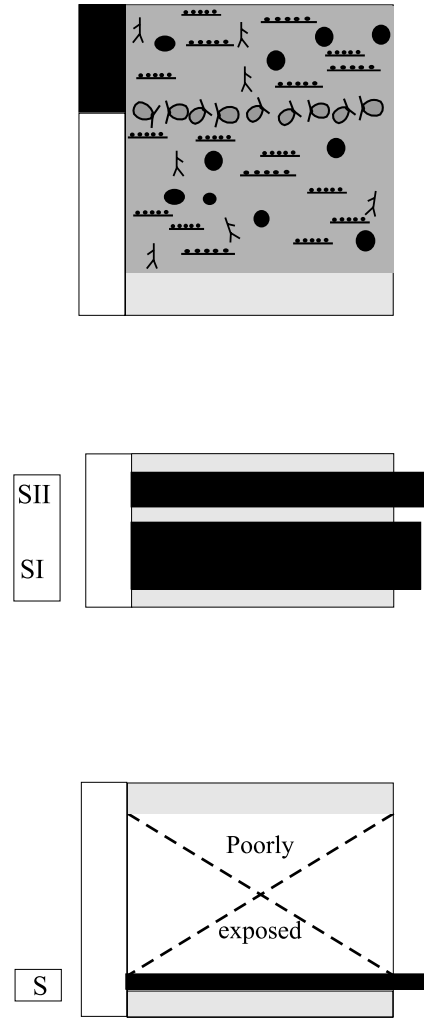

Epifauna (\%)
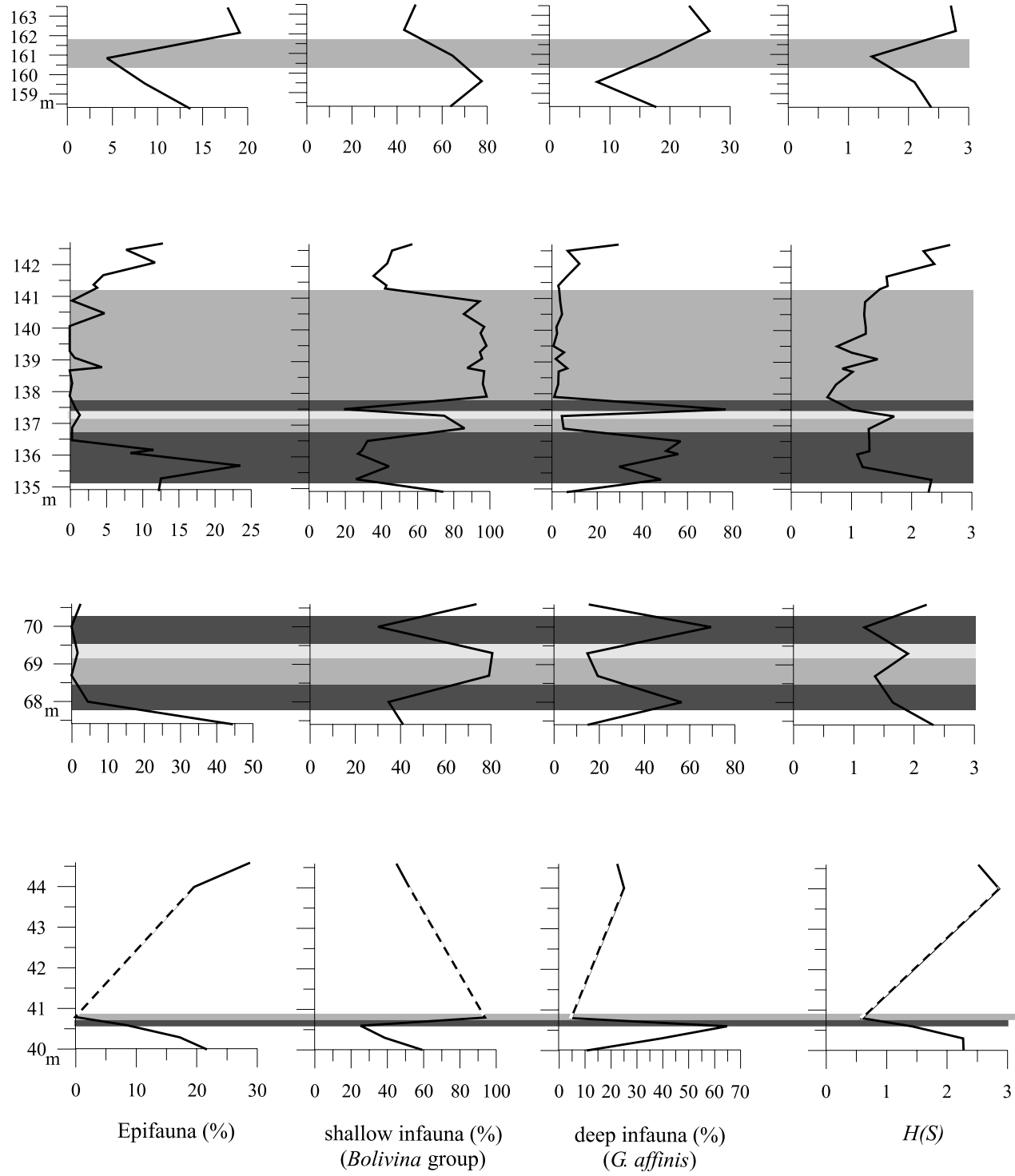

(G. affinis)

Interval enriched in Bolivina sp.

$H(S)$ increase

Interval enriched in G. affinis

Fig. 4. Distribution patterns across the intervals of strong oxygen depletion.

or poorly represented, and vice versa. The Uvigerina group 'costate forms' shows an opposite cyclical trend to $C$. carinata, $B$. marginata and Valvulineria $\mathrm{sp}$. The group has its maximum frequency in abundance in the stratigraphic interval around the volcaniclastic layer V4, from $125 \mathrm{~m}$ to $170 \mathrm{~m}$. It decreases in abundance in the following $30 \mathrm{~m}$ where, simultaneously, $A$. beccarii and the unkeeled Elphidium increase. Deep infauna is represented only by the Melonis and Textularia groups, which occur from $125 \mathrm{~m}$ upwards.

\section{Foraminiferal microhabitat distribution}

In Figure 6 the distributional patterns of epifauna, shallow and deep infauna and the $H(S)$ values are displayed throughout the Montalbano Jonico composite section. Epifauna is constantly present in the composite section. It disappears in the intervals documented as sapropels, where, conversely, the deep infauna component recorded its maximum frequency. The shallow infaunal position appears to be the most preferred by the Early-Middle Pleistocene foraminifera. Faunal diversities are 
Pleistocene foraminiferal microhabitats
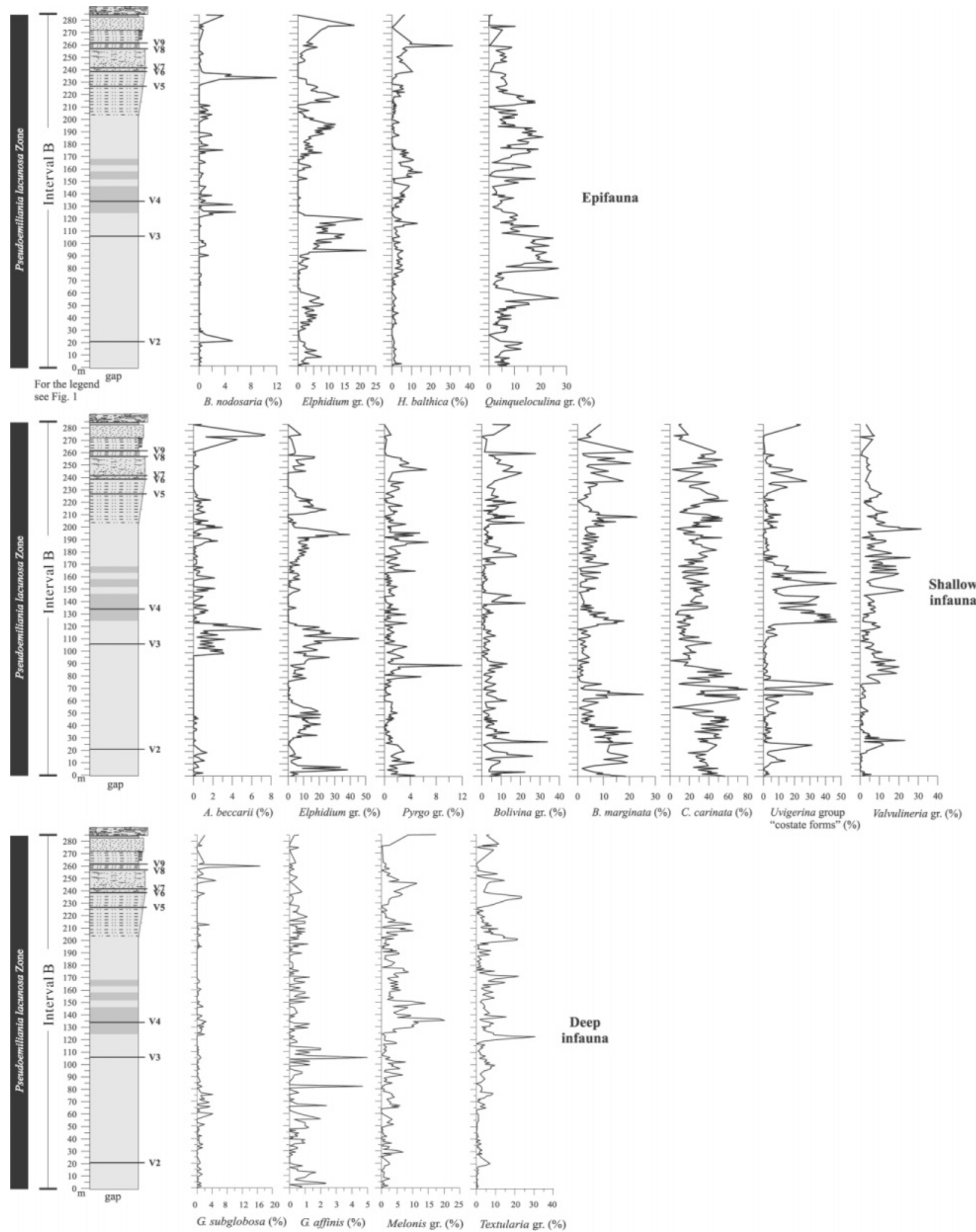

Fig. 5. Stratigraphic distribution of the most representative taxa in Interval B. 

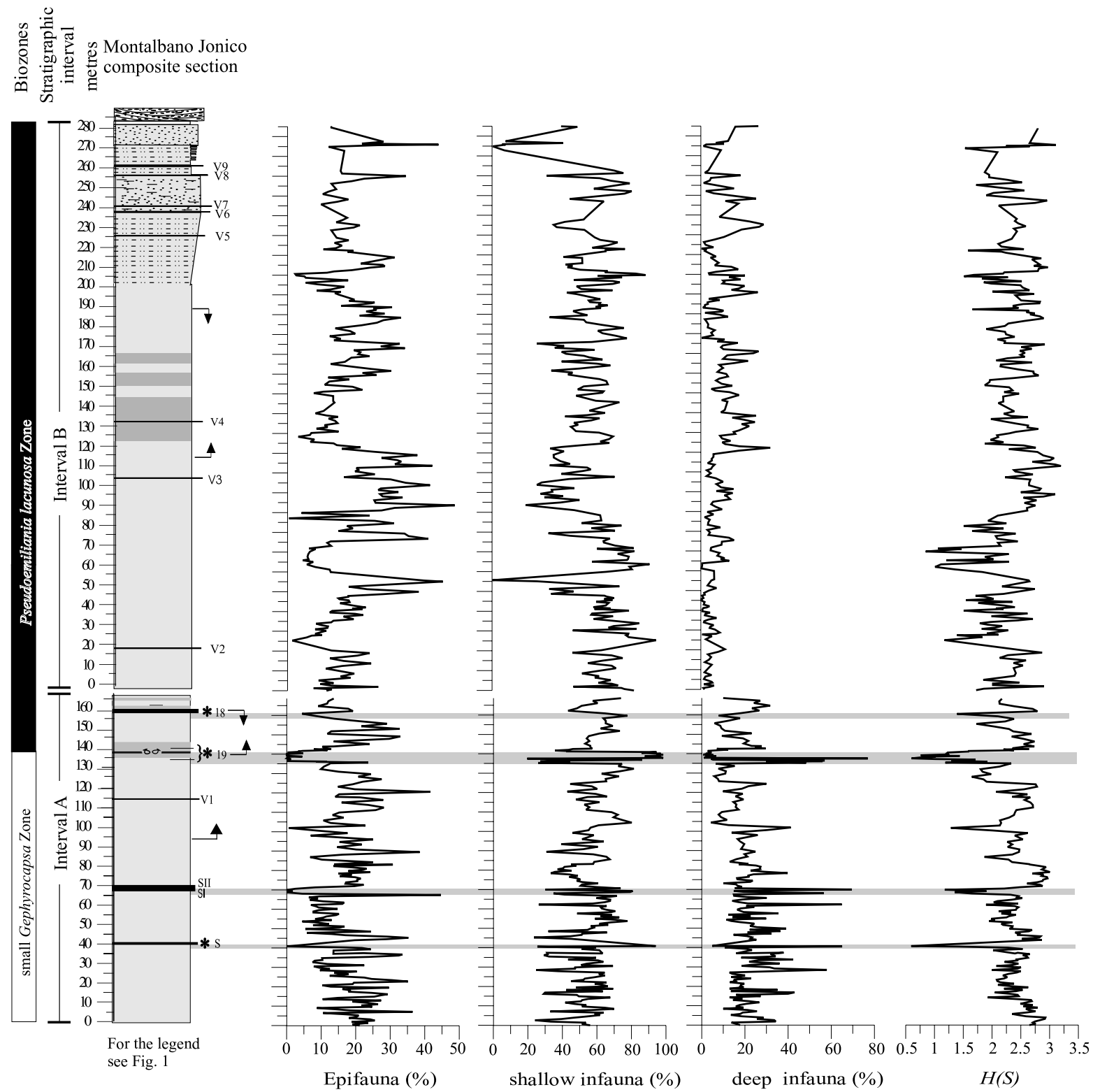

Fig. 6. Distribution patterns of the microhabitat preferences in the succession plotted with the Shannon Index. $H(S)$ is calculated using the program 'Past' (Hammer et al., 2001).

variable. In Interval A and in the lowermost part of Interval B the values decrease from $H(S)=3$ to $H(S)=0.7$, on average, in the intervals of sapropel deposition. In the remaining part of Interval $\mathrm{B}$, the faunas are well diversified with $H(S)$ values ranging between 3 and 2 .

\section{Palaeo-oxygen changes}

In Figure 7 the sample scores of Factor 3, the principal component extracted by principal component analysis for the composite section and reflecting oxygen variation (Stefanelli, 2003), is shown. It is plotted together with the palaeo-oxygen curve reconstructed using the Baas equation. Factor 3 reflects oxygen content since it is loaded by opposing indicators of oxygen. Cibicidoides and Elphidium group, reported to prefer the well-oxygenated marine bottom (Murray, 1991), show the highest positive loadings. Valvulineria sp., C. carinata, B. marginata and Bolivina sp., noted to prefer environments with moderate oxygen depletions in the bottom and pore-water sediments (Lutze \& Coulborn, 1984; Sen Gupta \& MachainCastillo, 1993; Rathburn \& Corliss, 1994), show the highest negative loadings. The graphic trend of the factor shows cyclic oxygen fluctuations, in which phases of 'good' oxygenation are alternated with phases of 'poor' oxygenation. In the generic trend, the factor is suggestive of better oxygenated conditions in Interval A when compared to Interval B.

In Interval A, the trend of the palaeo-oxygen curve is similar to the trend of Factor 3. The sole discrepancy is in the sapropel associated with I-cycle 86, where the factor indicates good oxygenation. Indeed, in this interval the sample score is distorted due to the scarcity of the benthic fauna. Only 


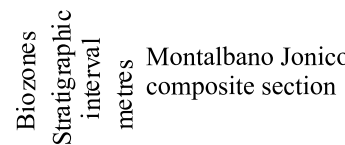

Oxygen concentration $\left(\mathrm{ml} \mathrm{l}^{-1}\right)$ at bottom water surface and in sediment assemblages

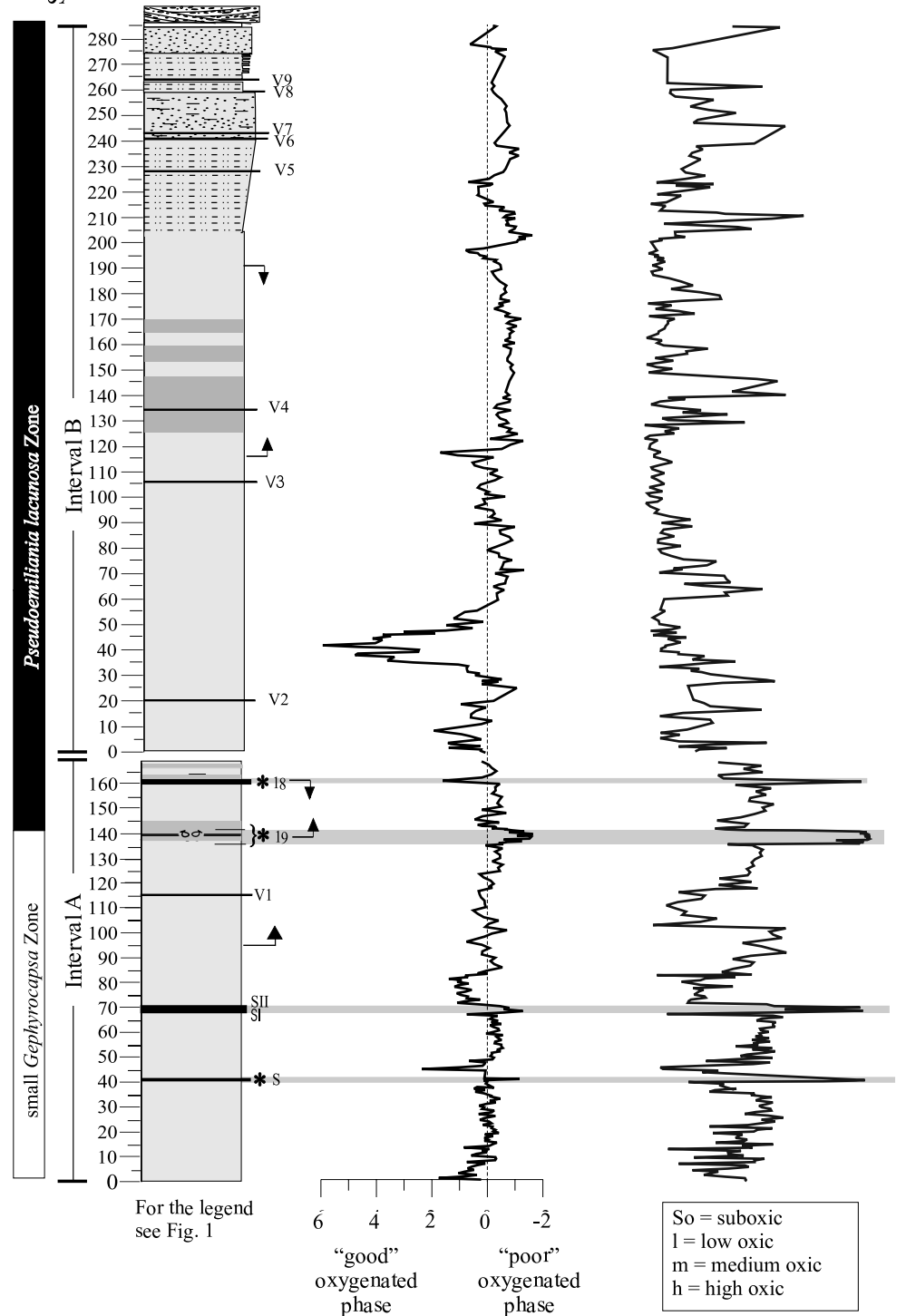

Fig. 7. Oxygen fluctuations reflected by the sample scores of Factor 3 and quantified by using Baas's equation. Factor 3 is one of the principal components extracted for the composite section performed by using PCA-analysis. The program SPSS version 9.0 was used for the Principal Component Analysis.

74 individuals were counted, 51 of which belong to the genus Bolivina. The palaeo-oxygen curve shows fluctuations in the high/medium oxic regime for the phases of 'good' oxygenation and low oxic condition for the phases of 'poor' oxygenation. In the intervals of sapropel deposition, the dissolved oxygen regime is interpreted as dysoxic.

In contrast, in Interval $\mathrm{B}$ the palaeo-oxygen curve reconstructs high/medium oxic regimes, suggesting better oxygenated conditions when compared with Interval A. Accordingly, the results appear to be clearly discordant with the sample scores of Factor 3. However, observing the general trend of the curves, they are similar. The sole most evident discrepancy is recorded in the stratigraphic portion above the volcaniclastic V4. Between $148 \mathrm{~m}$ and $180 \mathrm{~m}$, the palaeooxygen curve indicates a high oxic regime in the phase of 'poor' oxygenation. 


\section{DISCUSSION}

\section{Palaeoenvironmental implications}

Interval A. In the lower part of the Montalbano Jonico composite section, the distributional patterns of Cibicidoides and infaunal taxa delineate trends similar to those of the oxygen fluctuations. The decreasing trend in abundance of the former taxon and the increasing trends in abundance of the latter taxa seem to reflect well the reduction in the oxygenated levels towards the top. In the phases of 'good' oxygenation, one detects well-diversified faunas characterized by the presence of the epifaunal Cibicidoides sp. and $H$. balthica, together with the shallow infaunal $B$. marginata and $C$. carinata and the deep infaunal G. subglobosa, G. affinis and Melonis group. This vertical microhabitat distribution suggests that the bottom water is highly oxygenated and that the oxygen penetration, within the sediment column, reaches several centimetres, i.e. from $2 \mathrm{~cm}$ to $4 \mathrm{~cm}$ below the sediment surface (Loubere, 1997). This means that the redox zone is deep (Fig. 8a). In the 'poorly' oxygenated intervals, important changes in benthic assemblage compositions are detected. The faunas are less diversified, the epifaunal Cibicidoides sp. disappears and the assemblages are enriched in the infaunal component. The predominance of taxa having infaunal microhabitat preference suggests the reduction of the oxygen levels, linked to the shallowing of the redox zone. Cibicidoides sp. is commonly distributed in the modern stable marine waters and relatively rich in oxygen content (Murray, 1991) and reported to be intolerant of environmental stress, in particular oxygen deficiency at the bottom (van der Zwaan, 1983). Its disappearance indicates decreased oxygen availability at the bottom water, thus reducing oxygen penetration in the sediment column.

It is interesting to observe that Cibicidoides sp. and $H$. balthica have opposite distributional patterns. Though having the same shallow microhabitat position, these taxa occur in different oxygenated conditions. Indeed, F. J. Jorissen (pers. comm.) suggests that their patterns may be controlled by organic flux rather than oxygen content. Schmiedl et al. (2003) include H. balthica in the group of taxa together with B. dilatata, B. marginata, C. carinata and $G$. neosoldanii. They report these taxa as commonly distributed in mesotrophic to eutrophic environments. Hence, the shallowing of the redox front could be linked to the increase of food availability that leads to an increased consumption of oxygen (Jorissen et al., 1995) (Fig. 8b).

Also interesting is the distribution pattern of the Uvigerina group 'costate forms'. The group (dominated by $U$. peregrina) is commonly reported to tolerate oxygen-stressed conditions (Corliss, 1979; Verhallen, 1991). Gooday (1994) reported that the oxygen content of the overlying water masses, with $\mathrm{O}_{2}<2 \mathrm{ml} \mathrm{l}^{-1}$, seems to be the primary factor controlling its distribution. Indeed, in the Montalbano Jonico composite section, Uvigerina is detected with high percentages in the phases of 'good' oxygenation, thus, suggesting that it prefers oxygenated sediments. Yet, this ecological interpretation could be in good accordance with the opposite trend shown by $C$. carinata and $B$. marginata. These species are commonly found in environments with moderate oxygen depletion in the bottom and sediment pore-water (Lutze \& Coulborn, 1984; Sen Gupta \& Machain-Castillo, 1993; Rathburn \& Corliss, 1994).
Oxygen deficiency layers. When a further loss of oxygenation takes place, i.e. sapropels, the infaunal taxa that are less tolerant to low oxygen conditions are replaced by infaunal taxa with greater resistance to lower oxygen conditions. G. affinis, B. alata, $B$. dilatata and $B$. spathulata become the dominant species of these intervals, since all the other taxa cannot survive under highly stressed oxygen conditions. In this ecological setting, the redox zone is shallow and anoxic conditions are encountered $0.5 \mathrm{~cm}$ below the sediment surface (Loubere, 1997) (Fig. 8c).

The genera Globobulimina and Bolivina are known to characterize the sapropel-associated assemblages (Mullins et al., 1985; Nolet \& Corliss, 1990; Miao \& Thunell, 1993; Sen Gupta \& Machain-Castillo, 1993). G. affinis is reported to be the species 'most closely associated' with late Quaternary anoxia in the Mediterranean, found immediately below, above and occasionally within the sapropel (Mullineaux \& Lohmann, 1981; Nolet \& Corliss, 1990; Sen Gupta \& Machain-Castillo, 1993). Jorissen (1999) defines the species as 'especially resistant to low oxygen conditions'. B. alata is considered a shallow infaunal species preferring low-oxygen conditions and burrowing into sapropels (Cita \& Podenzani, 1980; Sen Gupta \& Machain-Castillo, 1993; Miao \& Thunell, 1993). In sediments, in which dissolved oxygen is below $0.3 \mathrm{ml}^{-1}$, Bolivina dominates the assemblage, exceeding 60\% (Mullins et al., 1985). The Bolivina genus, together with B. spathulata, is defined as a 'more opportunistic taxon, but less resistant to very low oxygen concentrations' (Jorissen, 1999). Barmawidjaja et al. (1992) consider the species B. spathulata among the taxa that increase in abundance when the total foraminiferal density decreases, probably because it is the most resistant, together with Bolivina, to lowered oxygen concentrations.

In the sapropel layers of the Montalbano Jonico succession, one observes the regular replacement of the deep infaunal $G$. affinis by the shallow infaunal Bolivina. Van der Zwaan \& Jorissen (1991) and Barmawidjaja et al. (1992) have suggested that deep infaunal species, under decreasing oxygen content, move up to the sediment-water interface, where they gradually replace the taxa that are less tolerant of oxygen content. The replacement of $G$. affinis by Bolivina may be suggestive of oxygen conditions pushed to minimum extreme at the bottom of the sapropels recorded in the Montalbano Jonico composite section and a relative improvement of oxygenation at the top. This palaeoenvironmental reconstruction appears to be plausible with the different recorded planktonic foraminiferal distributions. In intervals rich in individuals of G. affinis, the planktonic assemblages are dominated by the Globigerinoides ruber group, which indicates warm conditions and low salinity in surficial water masses (Capotondi \& Vigliotti, 1999). Conversely, in intervals rich in individuals of Bolivina, the decrease in abundance of the $G$. ruber group and the dominance of Globigerina bulloides and Neogloboquadrina dutertrei suggest cold and productive surface waters (Rohling et al., 1997; Negri et al., 2003).

In short intervals between SI and SII and within the sapropel associated with I-cycle 90, the decrease in abundance of G. affinis and Bolivina, simultaneously with the repopulation in the assemblage by the shallow taxa $C$. carinata and Uvigerina and the increase in $H(S)$ value, allows the identification of short time intervals in which sapropel deposition is interrupted (see Fig. 4). 
Pleistocene foraminiferal microhabitats

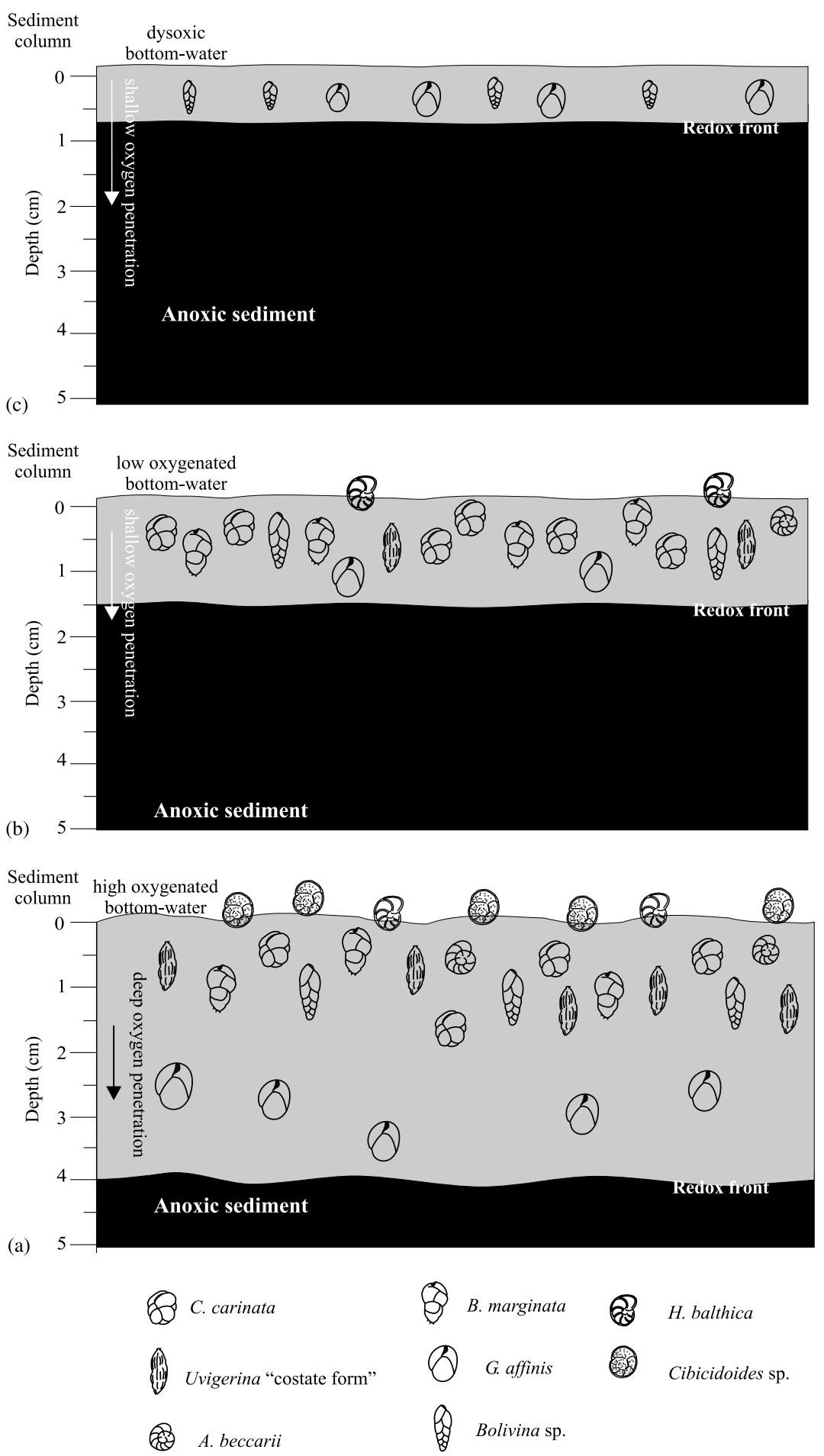

Fig. 8. Schematic reconstruction showing the microhabitat preferences with respect to the redox front position in the Montalbano Jonico composite section: (a) phases of 'good' oxygenation; (b) phases of 'poor' oxygenation; and (c) sapropel layers.

The change in the assemblage composition is suggestive of an improvement in oxygen content at the bottom water and of sediment pore-water that have caused a temporary deepening of the redox zone. The oxygen improvement is mirrored by the palaeo-oxygen curve from this study, which indicates a suboxic regime.
Interval B. In the shallow domain, the deep infaunal microhabitat is poorly represented. The low frequency of deep infaunal species is likely to be linked to the regressive trend of the sedimentary basin. G. affinis and G. subglobosa are commonly distributed in deep marine waters with depths greater than 100-150 m (Murray, 1991; Sgarrella \& Moncharmont Zei, 1993). 
In the phases of 'good' oxygenation, the assemblages are composed of epifaunal and infaunal taxa. The presence of Elphidium and Quinqueloculina group, associated with Ammonia group, C. carinata, B. marginata, the Uvigerina 'costate forms' group and Valvulineria sp., indicates the deep position of the redox zone within the sediment column. The palaeo-oxygen curve reconstructs a high oxic regime, thus, confirming the oxygen penetration at great depth. In the shallow areas of the Mediterranean Sea, the trophic levels are higher than in the deep areas (Jorissen et al., 1992; Schmiedl et al., 2000). This means that the consumption of oxygen is very high. In the northern and shallow Adriatic Sea, Jorissen et al. (1995) observed that, under eutrophic conditions, the depth of the microhabitats is not deeper than 1-2 cm below the sediment surface. In the phases of 'poor' oxygenation, one observes an increase in the infaunal position. As mirrored by the palaeo-oxygen curve, oxygen availability at the bottom-water interface and in the sediment pore-water, decreases. Consequently, the redox zone rises, thus, causing the disappearance of the epifauna.

It is interesting to observe the distributional patterns of the Uvigerina 'costate forms' group. With respect to Interval A, the Uvigerina group is frequent in the 'poorly' oxygenated intervals and disappears in the 'good' oxygenated phases. The cause that may explain this contradictory behaviour is the ability of Uvigerina to change its living depth. Studies conducted by Loubere et al. (1995) on the microhabitats of U. peregrina indicate that this species has productive populations at superficial and deeper infaunal levels within the sediments. Where bottom water oxygen content is low and the anoxic boundary in the sediment is shallow, the microhabitat of the $U$. peregrina population is shallow. If oxygen penetrates deeper into sediment, the population remains deeper infaunal. Accordingly, in Interval $\mathrm{B}$, its major occurrence in 'poorly' oxygenated phases supports the minor depth of the redox zone in the sediment column. In Interval A, its major frequency is related to the deeper position of the redox zone.

Also of note are the distributional patterns of the keeled and unkeeled Elphidium sp. These taxonomic groups, although living at different depths with respect to the sediment surface, are shown to have the same distribution in the stratigraphic interval. Since the unkeeled species can tolerate low oxygen conditions (Murray, 1991), their presence (at least with low frequency) should be plausible in the phases of 'poor' oxygenation. Furthermore, the oxygen decline is not so strong, i.e. medium oxic regime, to justify their total disappearance. The same dilemma emerges for Valvulineria sp. This taxon is an opportunistic species able to tolerate conditions of oxygen stress characterized by high percentages of organic matter and low oxygen concentration in the sediment (Jorissen, 1987; Bergamin et al., 1999). In this stratigraphic interval, the taxon shows an opposite trend to the other shallow infaunal taxa tolerating low oxygenated conditions. Valvulineria sp., from $55 \mathrm{~m}$ up to $75 \mathrm{~m}$ and, in the last $50 \mathrm{~m}$, decreases and/or disappears, contrarily, to C. carinata and B. marginata.

From the above observations, the author concludes that in a similar shallow sedimentary basin as the one reconstructed for Interval B in which wide sea-level fluctuations are recognized, the bathymetric effect cannot be ignored. In Figure 9 the oxygen fluctuations are plotted against the palaeodepth drawn from the stratigraphic distribution of the benthic foraminiferal assemblages (Stefanelli, 2003) and the oxygen isotope record (Brilli et al., 2000, and unpublished data). In Interval B, the sedimentary cyclicity has been linked to climate control (Ciaranfi et al., 2001). In the glacial periods, the shallowing phases correspond to the highly-oxygenated intervals; by contrast, in the interglacial period, the deepening phases correspond to the low oxygen conditions. As a consequence, the disappearance of Elphidium sp. and the increase in the Uvigerina group may be related to the shallowing of the redox zone as well as to the deepening of the sedimentary basin. The species of the genus Elphidium encountered in this study mainly live in shallow waters and disappear below $100 \mathrm{~m}$; their optimum is in the depth-range of 0-50 m (Murray, 1991; Sgarrella \& Moncharmont Zei, 1993). On the contrary, the costate forms of Uvigerina have an upper depth limit reported from about $100 \mathrm{~m}$ (Hasegawa et al., 1990).

The lowering of the sea-level is predicted to be not deeper than 110-120 m (D'Alessandro et al., 2003; Stefanelli, 2003). Consequently, the trophic conditions are unchanged when compared with the shallowing phases. This means that, in Interval B, the depth position of the microhabitat is not food-controlled, but is oxygen-controlled, in accordance with Jorissen et al. (1995).

\section{CONCLUSIONS}

The data from this study confirm that the position of the redox zone regulates the living depths of the Early-Middle Pleistocene benthic foraminifera. In the deep marine domain, the control on the composition and distribution of the fauna by the interplay between food availability and oxygen consumption is well supported. When oxygen availability is high and the anoxic boundary is deep, a distinct vertical microhabitat distribution is observed. As the trophic level increases, the oxygen demand increases and the redox zone rises. The epifauna disappears and, consequently, the infauna dominates the assemblages since it is more resistant to the low-oxygenated conditions. In consequence of a further oxygen loss, i.e. sapropels, the anoxic boundary is encountered immediately below the sediment surface and solely the opportunistic and more resistant taxa survive. By contrast, in the shallow marine domain in Interval B, which undergoes persistent eutrophic conditions, the depth of the microhabitats is controlled by oxygen availability. In addition to the oxygen-limited control, the wide sea-level fluctuations detected in this marine ecosystem also effect the vertical faunal distribution and composition.

Finally, the extracted curve of palaeo-oxygen drawn from Baas's equation, supports well the oxygen reconstruction made on the basis of taphofacies (Soldani, 2000) and macro benthic invertebrates (D'Alessandro et al., 2003), which suggests that Interval B was better oxygenated than Interval A. The overlap of the curve on the graph of the sample scores of Factor 3 shows that, in Interval B, the phases of 'poor' oxygenation, although having the same extent when compared with Interval A, do not reflect the same dissolved oxygen regime. Yet, the dissolved oxygen regime estimated in the phases of 'poor' oxygenation, in Interval $\mathrm{B}$, appears to be too high when compared with the faunal composition. In this ecological setting, i.e. high oxic regime, a major preference for the shallowest microhabitat 


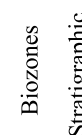

$\delta^{18} \mathrm{O} \% \mathrm{PDB}$

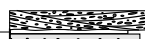

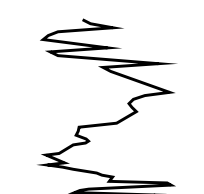
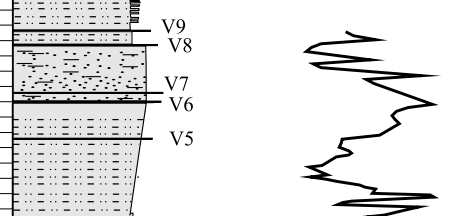

Factor 3

Oxygen concentration $(\mathrm{ml} / \mathrm{l})$ at bottom water surface and in sediment pore-waters by benthic foraminiferal
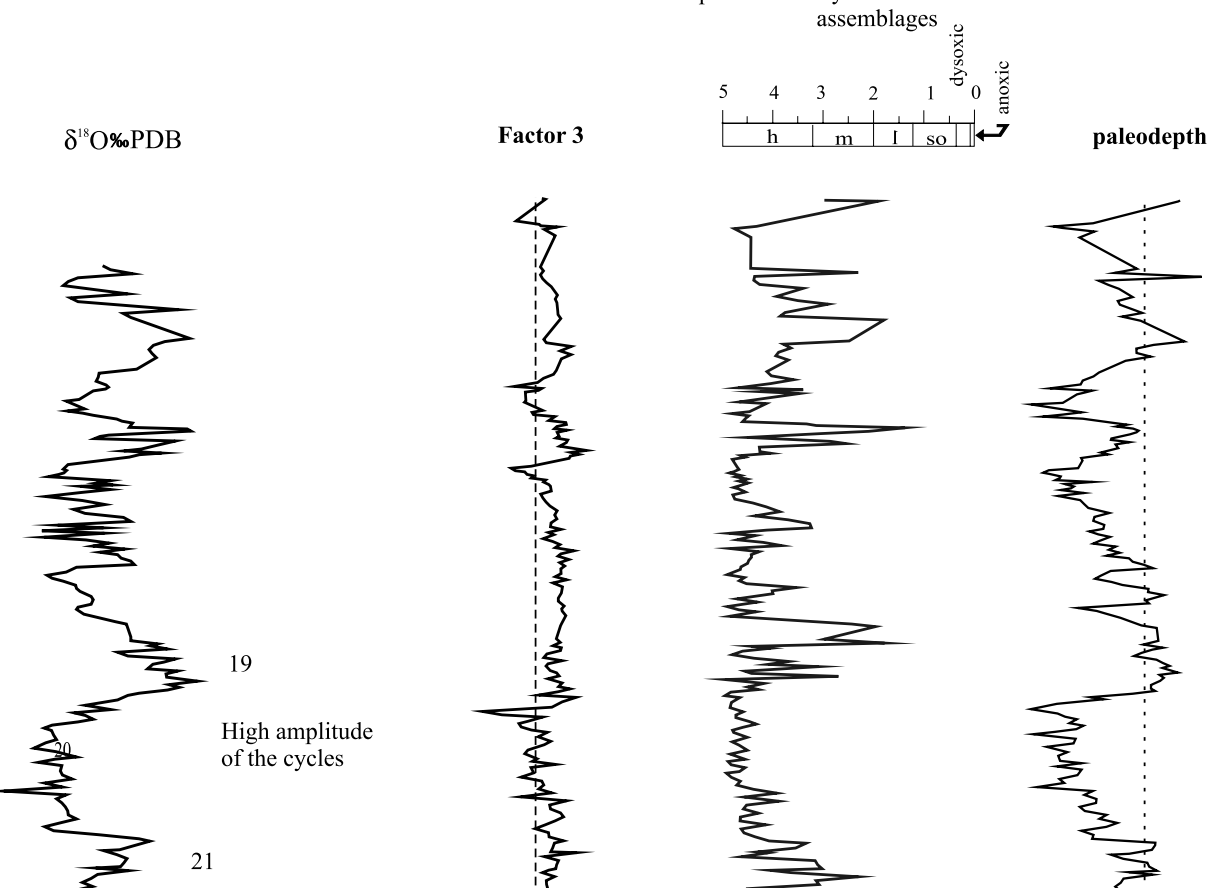

21

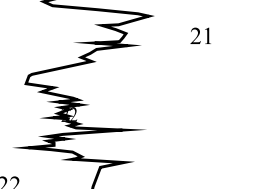

Change in amplitude and frequency
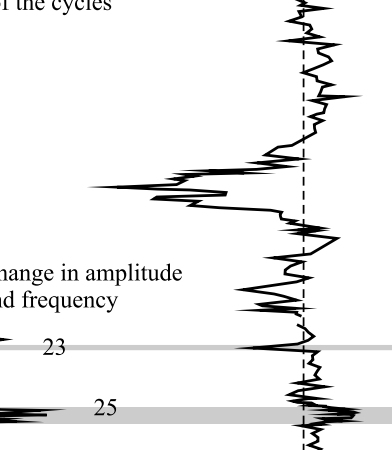

Low amplitude of the cycles

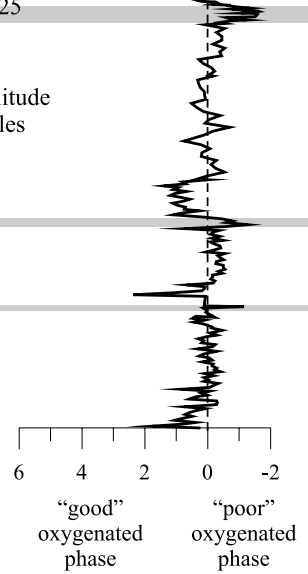

(Stefanelli, 2003)

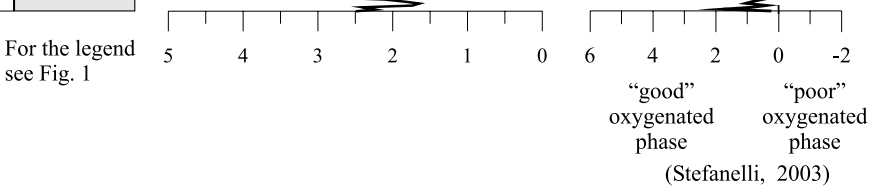

\section{So $=$ suboxic}

$1=$ low oxic

$\mathrm{h}=$ high oxic $\mathrm{m}=$ medium oxic

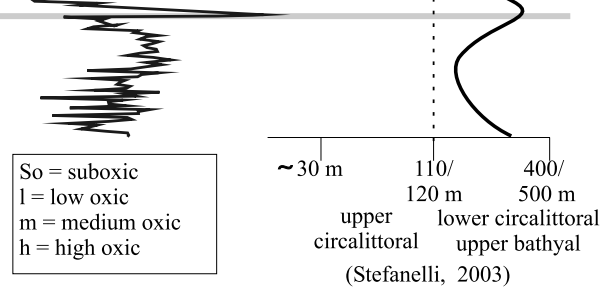

(Stefanelli, 2003)

Fig. 9. Sedimentary cyclicity recognized in the Montalbano Jonico composite section. The cyclicity is linked to the different pattern of climate variation and sea-level changes between the Early Pleistocene and Middle Pleistocene (Ciaranfi et al., 1997, 2001). The Early Pleistocene (Interval A) is dominated by cycles with low amplitude, linked to periodical obliquity, while the Middle Pleistocene (Interval B) is dominated by cycles with high amplitude connected to orbital eccentricity. In Interval B the glacioeustatic-controlled fluctuations are evident. For oxygen isotope analysis, the tests of Globigerina bulloides were used for Interval A and the tests of Cassidulina carinata for Interval B (Brilli et al., 2000, unpublished data). The palaeodepth is reflected by Factor 1, one of the principal components extracted for the composite section performed by using PCA-analysis. Palaeodepth and Factor 3 data from Stefanelli (2003).

position should be observed. The reason that may explain this discrepancy is the BFOI estimate. A faithful application of Kaiho's criteria appears not to be possible for the upper stratigraphic part of the composite section, probably, because of its deposition in a shallow sedimentary basin. By contrast, in the deep Interval A, generally better positive correlations can be 


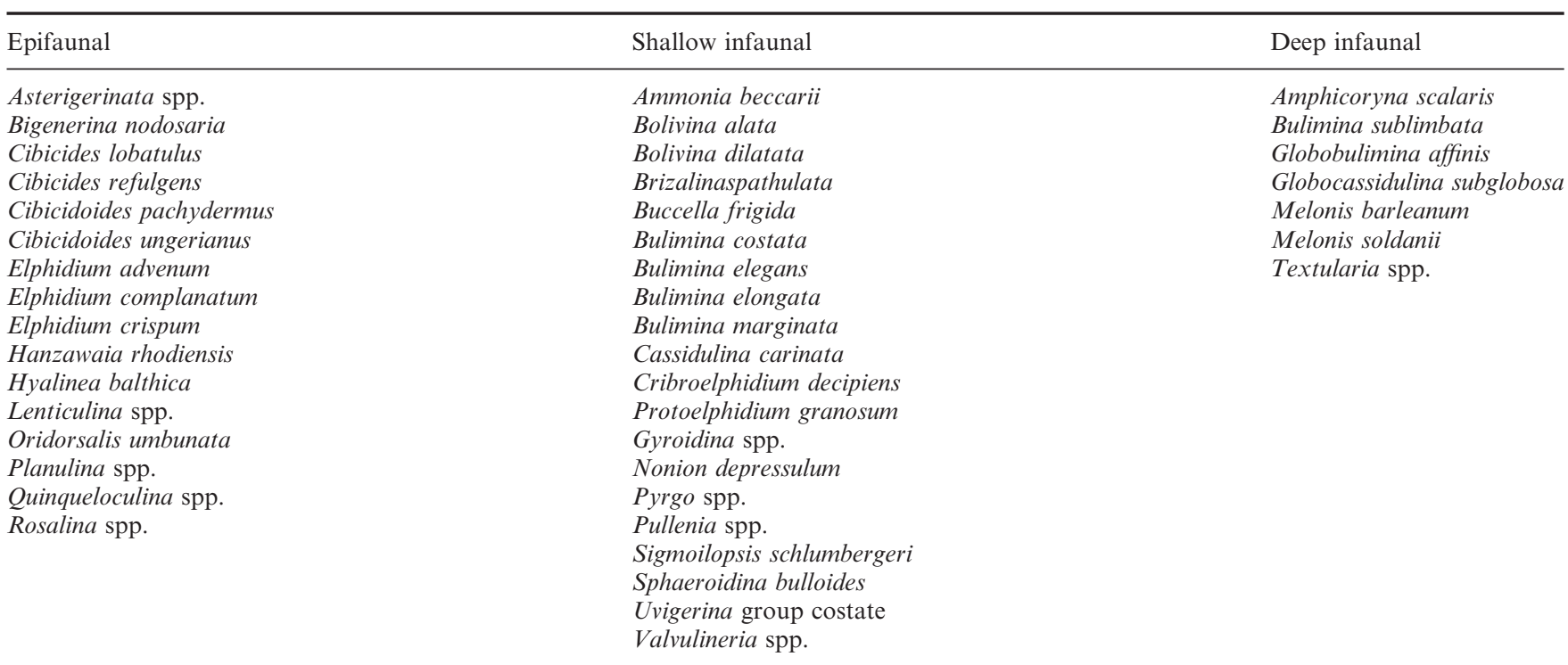

Table A1. Taxa encountered in the study grouped according to microhabitat.

detected, although the oxygen concentrations estimated appear to be too high when compared with the fossil fauna composition.

\section{ACKNOWLEDGEMENTS}

The author thanks Profs F. J. Jorissen and J. Murray for their helpful suggestions and corrections on the earlier versions of the manuscript. Thanks are also due to the reviewers for comments that improved the manuscript. Financial support was provided by University of Bari Grant ex 60\% (2003) to A. D'Alessandro concerning the project 'Paleoecologia e biostratigrafia di successioni quaternarie dell'Avanfossa sudappenninica'.

\section{APPENDIX A: TAXA GROUPINGS}

Table A1 lists the grouping of taxa encountered in this study on the basis of their microhabitat position. The subdivision was made following data from the literature (see text).

\section{APPENDIX B: PLEISTOCENE OXIC, SUBOXIC AND DYSOXIC INDICATORS}

Some of the Pleistocene oxic, suboxic and dysoxic indicators of Kaiho (1999) encountered in this study.

\section{Oxic indicators}

Cibicides refulgens, Cibicidoides pachydermus, Cibicidoides ungerianus, Globocassidulina subglobosa, Pyrgo spp. and Quinqueloculina spp.

\section{Suboxic indicators (group B)}

Bolivinita quadrilatera, Cassidulina carinata, Dentalina group, Lenticulina spp., Melonis spp., Nonion spp., Oridorsalis umbonatus, Pullenia spp., Sphaeroidina bulloides, Trifarina angulosa, Uvigerina spp. and Valvulineria spp.

\section{Dysoxic indicators}

Bolivina alata, Bolivina dilatata, Brizalina spathulata and Globobulimina affinis.

\section{Manuscript received 2 July 2003 Manuscript accepted 23 January 2004}

\section{REFERENCES}

Baas, J.H., Schönfeld, J. \& Zahn, R. 1998. Mid-depth oxygen drawdown during Heinrich event: evidence from benthic foraminiferal community structure, trace-fossil tiering, and benthic $\delta^{13} \mathrm{C}$ at the Portuguese margin. Marine Geology, 152: 25-55.

Barmawidjaja, D.M., Jorissen, F.J., Puskaric, S. \& van der Zwaan, G.J. 1992. Microhabitat selection by benthic foraminifera in the northern Adriatic Sea. Journal of Foraminiferal Research, 22(4): 297-317.

Bergamin, L., Di Bella, L. \& Carboni, M.G. 1999. Valvulineria bradyana (Fornasini) in organic matter-enriched environment (Ombrone River Mouth, Central Italy). Il Quaternario, 12(1): 51-56.

Brilli, M., Lerche, J., Ciaranfi, N. \& Turi, B. 2000. Evidence of precession and obliquity orbital forcing in Oxygen 18 isotope composition of Montalbano Jonico Section (Basilicata, Southern Italy). Applied Radiation and Isotopes, 52: 957-964.

Buzas, M.A. \& Gibson, T.G. 1969. Species diversity: benthonic foraminifera in Western North Atlantic. Science, 163: 72-75.

Buzas, M.A., Culver, S.J. \& Jorissen, F.J. 1993. A statistical evolution of the microhabitats of living (stained) infaunal benthic foraminifera. Marine Micropaleontology, 20: 311-320.

Capotondi, L. \& Vigliotti, L. 1999. Magnetic and microfaunistical characterization of late Quaternary sediments in the Western Mediterranean (ODP Leg 161). Inference on sapropel formation and paleoceanographic evolution. In: Zahn, R., Comas, M.C. \& Klaus, A. (Eds), Proceedings of the Ocean Drilling Program, Scientific Results, 161: $505-518$

Casnedi, R. 1988. La Fossa bradanica: origine, sedimentazione e migrazione. Memorie della Società Geologica Italiana, 41: 439-448.

Ciaranfi, N., Marino, M., Sabato, L., D’Alessandro, A. \& De Rosa, R. 1996. Studio geologico-stratigrafico di una successione infra e mesopleistocenica nella parte sud-occidentale della Fossa bradanica (Montalbano Jonico, Basilicata. Bollettino della Società Geologica Italiana, 115: 379-391.

Ciaranfi, N., D'Alessandro, A. \& Marino, M. 1997. A candidate section for the Lower-Middle Pleistocene Boundary (Apennine Foredeep, South Italy). In: Naiwen, Wang \& Remane, J. (Eds), Proceedings of the $30^{\text {th }}$ International Congress, 11: 201-211.

Ciaranfi, N., D'Alessandro, A., Girone, G., Maiorano, P., Marino, M., Soldani, D. \& Stefanelli, S. 2001. Pleistocene sections in the Montalbano Jonico area and the potential GSSP for Early-Middle Pleistocene in the Lucania Basin (Southern Italy). Memorie di Scienze Geologiche, 53: 67-83. 
Cita, M.B. \& Podenzani, M. 1980. Destructive effects of oxygen starvation and ash falls on benthic life: a pilot study. Quaternary Research, 13: 230-241.

Corliss, B.H. 1979. Recent deep-sea benthonic foraminiferal distribution in the Southern Indian Ocean: inferred bottom water routs and ecological implications. Marine Geology, 31: 115-138.

D’Alessandro, A., La Perna, R. \& Ciaranfi, N. 2003. Response of macrobenthos to changes in palaeoenvironments in the LowerMiddle Pleistocene (Lucania basin, southern Italy). volume speciale INQUAIl Quaternario, 16(1): 141-157.

Gooday, A.J. 1994. The Biology of Deep-Sea Foraminifera: A Review of Some Advances and Their Applications in Paleoceanography. Palaios, 9: 14-31.

Hammer, Ø., Harper, D.A.T. \& Ryan, P.D. 2001. PAST: Paleontological statistics software package for education and data analysis Palaentologia Electronica, 4(1): 9pp http://palaeo-electronica.org/ 2001_1/ past/issue.

Hasegawa, S., Sprovieri, R. \& Poluzzi, A. 1990. 29. Quantitative analysis of benthic foraminiferal assemblages from Plio-Pleistocene sequences in the Tyrrhenian Sea, ODP Leg 170. In: Kastens, K.A. \& Mascle, J. (Eds), Proceedings of the Ocean Drilling Program, Scientific Results, 107: 461-478.

Jorissen, F.J. 1987. The distribution of benthic foraminifera in the Adriatic sea. Marine Micropaleontology, 12: 21-48.

Jorissen, F.J. 1988. Benthic Foraminifera from the Adriatic Sea: principles of phenotypic variations. Utrecht Micropaleontological Bulletin, 34: 1-177.

Jorissen, F.J. 1999. Benthic foraminiferal succession across Late Quaternary Mediterranean sapropels. Marine Geology, 153: 91-101.

Jorissen, F.J. \& Wittling, I. 1999. Ecological evidence from livedead comparisons of benthic foraminiferal faunas off Cape Blanc (Northwest Africa). Palaeogeography, Palaeoclimatology, Palaeoecology, 149: 151-170.

Jorissen, F.J., Barmawidjaja, D.M., Puskaric, S. \& Van der Zwaan, G.J. 1992. Vertical distribution of benthic foraminifera in the northern Adriatic Sea: the relation with the organic flux. Marine Micropaleontology, 19: 131-146.

Jorissen, F.J., de Stigter, H.C. \& Vidmark, J.V. 1995. A conceptual model explaining benthic foraminiferal microhabitats. Marine Micropaleontology, 26: 3-15.

Kaiho, K. 1994. Benthic foraminiferal dissolved-oxygen index and dissolved-oxygen levels in the modern ocean. Geology, 22: 719-722.

Kaiho, K. 1999. Effect of organic carbon flux and dissolved oxygen on the benthic foraminiferal oxygen index (BFOI). Marine Micropaleontology, 37: 67-76.

Linke, P. \& Lutze, G.F. 1993. Microhabitat preferences of benthic foraminifera - a static concept or a dynamic adaptation to optimize food acquisition? Marine Micropaleontology, 20: 215-234.

Loubere, P. 1997. Benthic foraminiferal assemblage formation, organic carbon flux and oxygen concentrations on the outer continental shelf and slope. Journal of Foraminiferal Research, 27(2): 93-100.

Loubere, P., Meyers, P. \& Gary, A. 1995. Benthic foraminiferal microhabitat selection, carbo isotope values, and association with large animal: a test with Uvigerina peregrina. Journal of Foraminiferal Research, 25(1): 83-95.

Lutze, G.F. \& Coulborn, W.T. 1984. Recent benthic foraminifera from the continental margin of northwest Africa: community structure and distribution. Marine Micropaleontology, 8: 361-401.

Maiorano, P., Marino, M., Di Stefano, E. \& Ciaranfi, N. in press. Calcareous nannofossil events in the Lower-Middle Pleistocene transition at Montalbano Jonico section (Southern Italy) and ODP Site 964 (Ionian Sea), and their calibration with oxygen isotope and sapropel stratigraphy. Rivista Italiana di Paleontologia e Stratigrafia, $110(2)$.

Miao, Q. \& Thunell, R.C. 1993. Recent deep sea benthic foraminiferal distribution in the South China and sulu Seas. Marine Micropaleontology, 22: 1-32.
Mullineaux, L.S. \& Lohmann, G.P. 1981. Late Quaternary stagnations and recirculation of the Eastern Mediterranean: changes in the deep water recorded by fossil benthic foraminifera. Journal of Foraminiferal Research, 11(1): 20-39.

Mullins, H.T., Thompson, J.B., McDougall, K. \& Vercoutere, T.L. 1985. Oxygen-minimum zone edge effects: evidence from the central California coastal upwelling system. Geology, 13: 491-494.

Murray, J.W. 1991. Ecology and Palaeocology of Benthic Foraminifera. Longman Scientific \& Technical, 397pp.

Murray, J.W. 2001. The niche of benthic foraminifera, critical thresholds and proxies. Marine Micropaleontology, 41: 1-7.

Negri, A., Morigi, C. \& Giunta, S. 2003. Are productivity and stratification important to sapropel deposition? Microfossil evidence from Late Pliocene insolation cycle 180 at Vrica, Calabria. Palaeogeography, Palaeoclimatology, Palaeoecology, 190: 243-255.

Nolet, G.J. \& Corliss, B.H. 1990. Benthic foraminiferal evidence for reduced deep-water circulation during sapropel deposition in the eastern Mediterranean. Marine Geology, 94: 109-130.

Rathburn, A. \& Corliss, B.H. 1994. The ecology of living (stained) deep-sea benthic foraminifera from the Sulu Sea. Paleoceanography, 9: $87-150$.

Rohling, E.J., Jorissen, F.J. \& De Stigter, H.C. 1997. 200 Year interruption of Holocene sapropel formation in the Adriatic Sea. Journal of Micropaleontology, 16: 97-108.

Schmiedl, G., de Bovée, F., Buscail, R., Charrière, B., Hemleben, Ch., Medernach, L. \& Picon, P. 2000. Trophic control of benthic foraminiferal abundance and microhabitats in bathyal Gulf of Lions, western Mediterranean Sea. Marine Micropaleontology, 40: 167-188.

Schmiedl, G., Mitschele, A. \& Beck, S. 2003. Benthic foraminiferal record of ecosystem variability in the eastern Mediterranean Sea during times of sapropel $\mathrm{S}_{5}$ and $\mathrm{S}_{6}$ deposition. Palaeogeography, Palaeoclimatology, Palaeoecology, 190: 139-164.

Sen Gupta, B.K. \& Machain-Castillo, M.L. 1993. Benthic foraminifera in oxygen poor habitats. Marine Micropaleontology, 20: 183-201.

Sgarrella, F. \& Moncharmont Zei, M. 1993. Benthic foraminifera of the Gulf of Naples (Italy): systematic and autoecology. Bollettino della Società Paleontologica Italiana, 32(2): 145-264.

Soldani, D. 2000. Utilizzo e limiti di applicabilità delle tafofacies nelle analisi di bacino. $\mathrm{PhD}$ thesis. University of Bari, 86pp.

Stefanelli, S. 2003. Benthic foraminiferal assemblages as tools for paleoenvironmental reconstruction of the early-middle Pleistocene Montalbano Jonico composite section. Bollettino della Società Paleontologica, 42(3): 281-299.

Stefanelli, S., Capotondi, L. \& Ciaranfi, N. submitted. Foraminiferal record and environmental changes during the deposition of the earlymiddle Pleistocene sapropels in southern Italy. Palaeogeography, Palaeoclimatology, Palaeoecology.

Verhallen, P.J.J.M. 1991. Late Pliocene to Early Pleistocene Mediterranean mud-dwelling Foraminifera; influence of a changing environment of community structure and evolution. Utrecht Micropaleontological Bulletin., 40: 1-219.

van der Zwaan, G.J. 1983. Quantitative analyses and the reconstruction of benthic foraminifera communities. Utrecht Micropaleontological Bulletin, 30: 49-69.

van der Zwaan, G.J. \& Jorissen, F.J. 1991. Biofacial patterns in river-induced shelf anoxia. In: Tyson, R.V. \& Pearson, T.H. (Eds), Modern and Ancient Continental Shelf. Geological Society, London, Special Publications, 58: 65-82.

van der Zwaan, G.J., Duijnstee, I.A.P., Den Dulk, M., Ernest, S.R., Jannink, N.T. \& Kouwenhoven, T.J. 1999. Benthic foraminifers: proxies or problems? A review of paleoecological concepts. Earth Science Reviews, 46: 213-236. 